\title{
YERLİ VE YABANCI SERMAYELİ İŞLETMELERÍN KÂRLILIKLARININ KARŞILAŞTIRILMASI: TÜRKİYE'DEKİ BÜYÜK ÜRETİCİ FİRMALAR ÖRNEĞİ
}

\author{
Aytuğ SÖZÜER*, Esin Bengü CERAN**, Fatih SEMERCİÖZ*** \\ Öz
}

$\mathrm{Bu}$ çalışma, işletmelerin sermaye yapısında yabancı iştirak bulunmasının firma performansıyla ilişkili olup olmadığına dair, mevcut yazında devam eden tartışmaya katkı sağlamayı amaçlamaktadır. Çalışmanın öngörüsü, büyük ve yerleşik işletmeler arasındaki taşma (yayılma) etkisi dikkate alındığında, yerli ve yabancı sermayeli firmaların ekonomik getirilerinin eşdeğer olduğudur. Görgül araştırma için İstanbul Sanayi Odasının hazırladığı Türkiye'nin en büyük sanayi kuruluşları listeleri ikincil veri olarak kullanılmıştır. Bulgular, yerli ve yabancı sermayeli işletmelerin özellikle aktif kârlılıkları açısından eşdeğer performans gösterdikleri hipotezini desteklemektedir. Çalışmanın, Türkiye'deki bir grup büyük sanayi kuruluşunun ekonomik getirilerinin hangi aralıkta dağıldığını tespit etmesi açısından özgün değer taşıdığı düşünülmektedir.

Anahtar Sözcükler: Doğrudan Yabancı Yatırımlar, Yerli İşletmeler, Taşma Etkisi, İşletme Performansı

\section{COMPARING THE PROFITABILITY OF FIRMS WITH DOMESTIC AND FOREIGN CAPITAL: THE CASE OF BIG MANUFACTURERS IN TURKEY \\ ABSTRACT}

This study is an attempt to expand the ongoing research on the relationship between foreign equity and firm performance. The study anticipates the economic performances of firms with foreign and domestic capital are equivalent. Conceptually, this premise is based on the spillover effects among large entities in a given economy. For the empirical analysis, the lists of the largest industrial companies in Turkey prepared by Istanbul Chamber of Industry were used as secondary data. Findings support the hypothesis that firms with either foreign or domestic capital perform likewise, particularly in terms of return on assets indicator. The study offers relevant value at least by determining the range of profitability of big industrial firms in Turkey.

Keywords: Foreign Direct Investments, Domestic Firms, Spillover Effect, Firm Performance

\footnotetext{
* Yalova Üniversitesi, İktisadi ve İdari Bilimler Fakültesi, Merkez Kampüs, Yalova, E-posta: aytug.sozuer@yalova.edu.tr

** İstanbul Üniversitesi, İşletme Fakültesi, Avcılar Kampüs, İstanbul, E-posta: esinbenguceran@istanbul.edu.tr

*** İstanbul Üniversitesi, İşletme Fakültesi, Avcılar Kampüs, İstanbul, E-posta: fsemerci@istanbul.edu.tr
} 
Yerli ve Yabancı Sermayeli İşletmelerin Kârlılıklarının Karşılaştırııması: Türkiye'deki Büyük Üretici Firmalar Örneği

\section{GİRIŞ 1}

Dünyada doğrudan yabancı yatıım stoku, 2016 yılı itibariyle, 26 trilyon ABD Dolarının üzerinde hesaplanmaktadır. Türkiye'nin bu sermaye birikiminden aldığı pay ise, 2000-2016 döneminde \%0,25'ten \%0,50'ye çıkmışır (UNCTAD, 2017). Mütevazı gözüken bu oran, aslında ülke sınırları içinde 53.000'nin üzerinde yabancı sermayeli şirket ve 133 milyar ABD Doları civarında uluslararası doğrudan yatıımı işaret etmektedir. Bu hacimdeki sermaye birikimi, reel ekonomide belirgin bir derinlik oluşturmakta ve piyasa hareketlerini etkilemektedir.

Türkiye Cumhuriyeti 1950 'li yıllarda yürürlüğe konan kanunlarla yabancı sermayeyi teşvik etmeye çalışmış; 1980'li yıllarda uygulanan neoliberal politikalarla da ekonomisi dışa açılmaya başlamıştır. Türkiye ile Avrupa Birliği (AB) arasında 1995 yılında imzalanan Gümrük Birliği anlaşması, 1999 yılında $A B^{\prime} y e$ adaylığın onaylanması ve 2005 yılında girilen üyelik müzakere süreci, Türkiye'ye yapılan doğrudan yabancı yatırımları kolaylaştıran kurumsal dönüşümlere etki eden faktörlerdir (Koçtürk ve Eker, 2012; Togan, 2010). Günümüzde, bu tip ekonomik dışa açılımların ülke piyasalarına verimlilik getirdiği görüşü yaygındır.

Uluslararası ticaret dünya tarihinde çok eskilere gitse de, işletmelerin uluslararası faaliyetlerinin akademide kuramsallaşması 1960 'lardan itibaren belirginleşmiştir (Rugman, Verbeke ve Nguyen, 2011). Ülkelerin, işletmelerin ve bunların yurt dışındaki iştiraklerinin özellikleri ve aralarındaki bağlantılar hakkında; Hymer (1960), Vernon (1966), Buckley ve Casson (1976), Dunning (1977), Johanson ve Vahlne (1977), Hennart (1982), Johanson ve Mattson (1988) ve Birkinshaw (1996, 1997) alanda akım yaratmış eserlere örnek gösterilebilir. Uluslararası işletmecilik açısından, şirketlerin yabancı ülkelerde mülkiyet temelli (örneğin ortaklık) veya mülkiyet temelli olmayan (örneğin ihracat) biçimde faaliyet gösterme kararı ve bunun sonuçları da önemli bir konuyu temsil etmektedir (Werner, 2002). Öte yandan, bu konu hakkında halen açıklığa kavuşmamış noktalar olduğu ve özellikle işletmelerin pazara giriş yöntemleri ile o pazardaki performansları arasında sınırlı sayıda çalışma bulunduğunun altı çizilmektedir (Brouthers ve Hennart 2007; Canabal ve White, 2008; Morschett, Schramm-Klein ve Swoboda, 2010).

${ }^{1}$ Bu çalışmanın özeti, 24. Ulusal Yönetim ve Organizasyon Kongresi'nde (İstanbul, 29-31 Mayıs 2016) "Yabancı sermaye işletme yönetimini etkin kılar mı? Sanayi kuruluşlarının finansal göstergeleri açısından bir değerlendirme" başıklı bildiri olarak sunulmuştur. 


\section{Aytuğ Sözüer, Esin Bengü Ceran ve Fatih Semerciöz}

Doğrudan yabancı yatırımlar, çoğunlukla, uluslararası şirketlerin yeni kaynaklar, pazarlar veya değer zincirlerinde verimlilik arayışıyla, farkı ülkelerdeki yatırımlarından ortalama üstü getiri beklentisiyle gerçekleşmektedir. Doğal olarak bu şirketler, sermaye aktararak risk aldıkları yabancı pazarlarda, rakiplerine kıyasla daha yüksek performans hedeflemektedir. Bu beklentilerin sonuçları ve öncesindeki dinamikler ise, yönetim ve strateji yazınının da ilgi alanlarından biri halindedir.

Bu çalışmanın amacı, uluslararası işletmelerin, var olduğu kabul edilen kendilerine özgü üstünlüklerinin, mülkiyet temelli biçimde faaliyet gösterdikleri yurt dışı pazarlarda yerel rekabete karşı, günümüz koşullarında bir avantaj sağlayıp sağlamadığını anlamaktır.

Devam eden bölümlerde öncelikle mevcut yazındaki bilgi ve yaklaşımlar aktarılacak; ardından Türkiye'deki yabancı sermayeli işletmelerin elde ettikleri ekonomik sonuçları yerli işletmelerle karşılaştıran hipotez test edilecek ve bulgular değerlendirilecektir.

\section{YAZIN İNCELEMESİ VE ARAŞTIRMA HİPOTEZİ}

Uluslararası işletmecilik yazınının erken dönemlerinde, Hymer'in (1960) işaret ettiği üzere, yurt dışında faaliyet gösteren işletmelerin, gittikleri ülkedeki kültürel, ekonomik, hukuki ve benzeri koşullara yabancı olmalarından ötürü rekabete dezavantajlı başladıkları kabul edilmekteydi. Daha sonraları, çokuluslu işletmeler kapsamlarını genişlettikçe durumun tersine döndüğü varsayımı güçlendi. Çokuluslu işletmelerin kendilerine özgü üstünlüklerini yurt dışındaki iştiraklerine aktararak yerli firmalarla rekabette öne geçtikleri ortaya kondu (Caves, 1996; Dunning, 1993; Markusen, 1995). Bu büyük işletmelerin teknolojik bilgi birikimi, ölçek ekonomisi, tedarik ve pazarlama ağı, genel yönetim becerisi ve yüksek itibar gibi özellikleriyle, yatırım yaptıkları ülkelerde yerli rakiplerine kıyasla daha başarılı oldukları vurgulanmaya başlandı (Aitken ve Harrison, 1999; Helpman, Melitz ve Yeaple, 2004; Yeaple, 2003). Yakın dönemde, geçiş ekonomileri ve gelişmekte olan ülkelerde yapılan görgül araştırmalar da bu tezi desteklemekteydi (ör. Yaşar ve Paul, 2007; Notta ve Vlachvei, 2008; Liu, Lu ve Qiu, 2017). Öte taraftan, bu bulgunun her zaman geçerli olmadığı da ortaya çıktı. Benzer dönemde fakat farklı bağlamlarda yapılan bazı araştırmalar, işletmelerdeki yabancı sermaye varlığı ile kurumsal performans arasında anlamlı ilişki tespit edemedi (ör. Barbosa ve Louri, 2005; Gedajlovic, Yoshikawa ve Hashimoto, 2005; Mihai ve Mihai, 2013). Hatta başka çalışmalarda, işletme performansında yabancı sermayenin hangi ülkeden geldiği, hangi sektörlerde tecrübeli olduğu veya ev sahibi 


\section{Yerli ve Yabancı Sermayeli İşletmelerin Kârlılıklarının Karşılaştırılması: Türkiye'deki Büyük Üretici Firmalar Örneği}

ülkede ortak olduğu işletmeyi nasıl seçtiği gibi daha komplike faktörlerin rol oynadığına işaret edilmekteydi (Chen ve Hu, 2002; Douma, George ve Kabir, 2006; Bilyk, 2009).

Yukarıda bahsedilen çalışmaların sonuçlarındaki çeşitlilik, yazında konu hakkında bir mutabakat olmadığını göstermektedir. Bu durum büyük olasılıkla, araştırmaların kapsam ve tasarımlarındaki farklılıklara dayanmaktadır. Diğer yandan, benzer araştırma sorularıyla yola çıkmış ve analizlerini Türkiye bağlamında (özellikle İstanbul borsasında işlem gören işletmeler üzerinde) yapmış çalışmalar da mevcuttur. Bunlara daha detaylı bakılacak olursa; Aydın, Sayım ve Yalama (2007) 42 yabancı sermayeli işletme ile 259 yerli işletmenin 2003-04 yıllarındaki finansal göstergelerini kıyaslamış ve aktif kârlıık açısından yabancı sermayeli işletmelerin daha başarılı olduğunu tespit etmiştir. Basti ve Bayyurt (2008) 46 yabancı sermayeli firma ile 139 yerli firmanın 2006 yılı verilerini verimlilik ölçütlerine göre karşılaştırmış ve yabancı sermayeli firmaların daha üstün olduğunu göstermiştir. Gürbüz ve Aybars (2010) 205 firmanın 2005-07 yılları arasındaki verilerini incelediğinde; yerli işletmelere kıyasla, sermaye yapısında yabancı iştirakinin azınlıkta olduğu işletmelerin daha yüksek, çoğunlukta olduğu işletmelerin ise daha düşük performans gösterdiğini tespit etmiştir. Ertuna ve Yamak (2011) 164 işletmenin 1999-2002 dönemindeki performanslarını yabancı iştirak düzeylerine göre irdelemiş; eşit paylaşılan sermaye yapısının, yabancı ortaklığın çoğunlukta veya azınlıkta bulunmasından daha avantajlı olduğunu göstermiştir. Bu örneklere bakıldığında da yabancı sermayeli işletmelerin yerli olanlar karşısında kesin bir üstünlük sağladığından bahsedilememektedir.

$\mathrm{Bu}$ noktada, yerli ve yabancı sermayeli işletmelerin performans değerlendirmesi konusuna değişik bir açıdan yaklaşmanın, özellikle Türkiye bağlamındaki incelemelere derinlik katacağı düşünülmektedir. Göz önüne alınması gereken başlıca konulardan biri, ülkede faaliyet gösteren yabancı sermayeli işletmelerin yerli rakipleri üzerindeki dolaylı etkileridir. Yazında, taşma olarak geçen bu dolaylı etkiler, rekabetin dinamiklerini etkileyen önemli bir unsurdur. Taşma, bir yönüyle, uluslararası işletmelerin rekabette fark yaratacağı düşünülen özelliklerinin, zaman içinde ve çeşitli yollarla yerli işletmelere geçişini yansıtmaktadır. Literatürde, taşmanın; taklitçilik, işgücü hareketliliği ve rekabet etkisi aracilığıla olabileceği tespit edilmiştir. Bunlar kısaca açıklanacak olursa; yerli işletmeler, uluslararası işletmelere yakın oldukça, onların çeşitli faaliyetlerini izleyerek ve bunları taklit ederek, yurt dışında da iş yapmayı öğrenebilmektedir. Ayrıca, uluslararası işletmeler, faaliyet gösterdikleri piyasalarda kendi teknoloji ve uygulamalarını 


\section{Aytuğ Sözüer, Esin Bengü Ceran ve Fatih Semerciöz}

yürütmek için çalışanlarını eğitmek durumundadır. Böylece, o ülkede donanımlı işgücü oluşur ve yerli işletmeler bu çalışanları transfer ettiğinde önemli bir bilgi aktarımı gerçekleşir. Bunlarla birlikte, uluslararası işletmeler kendi teknolojisi ve kaynaklarıyla yurtdışında belirli bir sektöre giriş yaptığında, o alanda faaliyet gösteren yerli işletmeler, rekabette ayakta kalabilmek adına, verimlilik veya çeşitlendirme yatırımları yaparak iyileşme yoluna gidebilir. Bu mekanizmalar sayesinde, uluslararası işletmelerin dolaylı olarak yerli rakiplerini geliştirdiği düşünülmektedir (Bruno ve Cipollina, 2014). Taşma etkisi, kuramsal kuramda yer alan, aynı koşullar altındaki örgütlerin zamanla benzer yapısal ve davranışsal özellikler gösterebileceğini öne süren eşbiçimlilik (DiMaggio ve Powell, 1983) olgusuyla da uyumludur. Ayrıca, gelişmekte olan ekonomilerde (Yaşar ve Paul, 2007) ve hatta Türkiye sanayi sektöründe (Aslanoğlu, 2000) bu taşma etkisinin varlığına dair bulgular da mevcuttur.

Alandaki çalışmaların ışığında ve yukarında bahsedilen taşma etkisiyle, bu çalışmanın beklentisi aşağıdaki gibidir.

Hipotez: Büyük işletmeler dikkate alındığında, yabancı sermaye iştiraki olan şirketler ile yerli sermayeli şirketlerin ekonomik getirileri eşdeğerdir.

\section{ARAŞTIRMA YÖNTEMİ VE BULGULAR}

Bu çalışmaya ilişkin analiz için İstanbul Sanayi Odasının hazırladığı Türkiye'nin Birinci ve İkinci 500 Sanayi Kuruluşu araştırmalarından özel bir veri seti derlenmiştir. Kökeni 1968 yılına dayanan bu araştırmalar, 1998 yllından bugüne Türkiye'nin 1.000 büyük sanayi kuruluşunu kapsayacak biçimde yürütülmekte ve kamuoyu ile paylaşılmaktadır. Ayrıca, bu veriler pek çok akademik araştırmaya da önemli veri kaynağı sağlamaktadır (İso, 2017a).

Öncelikle, bir pilot test olması açısından, 2015 yılı için hazırlanan Birinci 500 Sanayi Kuruluşu listesinde net satışları ile dönem kârı/zararı açıklanmış 173 adet $\% 100$ yerli sermayeli firma ile 42 adet $\% 10$ ve üzeri yabancı sermaye iştirakli firmanın kârlıık oranları hesaplanmıştır (İSO, 2017b). Bağımsız grup t testi sonucunda bu iki tip işletme arasında kârlıık bakımından belirgin bir fark olmadığı tespit edilmiştir $(p=0,12, \% 95$ güven aralığında). Böylece, bir sonraki aşamada daha nitelikli analizlere geçilmesi uygun görülmüştür.

İşletme performansı değerlendirmelerinde, objektif ölçütler olarak, aktif (varlık) kârlıık (ROA) ve özkaynak getirisi (ROE) sıkça kullanılan oranlardır (Al-Matari, Al-Swidi ve Fadzil, 2014). Bu muhasebe temelli oranlar, işletmenin varlıklarına ve özsermayesine kıyasla ne ölçüde kâr elde 
Yerli ve Yabancı Sermayeli İşletmelerin Kârlılıklarının Karşılaştırılması: Türkiye'deki Büyük Üretici Firmalar Örneği

ettiğini göstermesi açısından, bir yönüyle, işletme yönetiminin etkinliğini yansıtmaktadır. Bu çalışma için veri seti düzenlenirken, performans olgusunun stratejik yönünü dikkate almak ve güncel bir kesit ortaya koyabilmek adına üç yıllık orta vadeli bir dönemin kapsanması makul görülmüştür. Yakın tarihli ve azami sayıda gözlem elde edebilmek için de, 2011, 2012 ve 2013 yıllarında aktif, özkaynak ve net kâr/zarar bilgileri açıklanmış, \%10 ve üzerinde yabancı sermaye iştirakine sahip işletmeler listelenmiştir. Bunlar arasından, ilgili üç yıl boyunca yabancı sermaye oranının azınlıktan çoğunluğa, çoğunluktan azınlığa geçtiği veya hisselerin tamamen tasfiye edilmesi şeklinde büyük değişikliklere uğramamış olanlar süzülmüştür. Sonuçta, sermaye yapısının nispeten istikrarlı olduğu ve üç yıllık ortalama performans göstergelerinin hesaplanabileceği 70 işletme verisi elde edilmiştir. İşletmelerin 33'ünde yabancı sermaye iştiraki \%50'nin altındadır. Bu grup işletme ile anlamlı bir karşılaşı̧ıma yapabilmek için araştırmalarda aynı dönemlere ait verileri açıklanmış $\% 100$ yerli sermayeli 70 işletme, faaliyet alanı ve satış hacmi en yakın olma kıstaslarına göre, yargısal biçimde eşleştirilmiştir. Böylece, çalışma için 20 farklı faaliyet kolundan 140 işletmeyi kapsayan bir veri seti oluşmuştur. Örneklem grubundaki işletmelerin 2013 yıına ait diğer tanımlayıcı bilgileri Tablo 1'de sunulmuştur.

Tablo 1: Örneklemin 2013 Yılı Satış Hacmi ve Çalışan Sayıları

\begin{tabular}{|c|c|c|c|}
\hline \multicolumn{4}{|c|}{ Şirket sayısı } \\
\hline $\begin{array}{l}\text { Net satışlar } \\
\text { (Milyon TL) }\end{array}$ & Yerli sermayeli & $\begin{array}{c}\text { Yabancl } \\
\text { sermayeli }\end{array}$ & Toplam \\
\hline$<100$ & 1 & 2 & 3 \\
\hline $100-499$ & 45 & 44 & 89 \\
\hline $500-1.000$ & 15 & 12 & 27 \\
\hline$>1.000$ & 9 & 12 & 21 \\
\hline Toplam & 70 & 70 & 140 \\
\hline \multicolumn{4}{|l|}{ Çalışan sayısı } \\
\hline$<100$ & 3 & 2 & 5 \\
\hline $100-249$ & 14 & 12 & 26 \\
\hline $250-500$ & 17 & 16 & 33 \\
\hline$>500$ & 36 & 40 & 76 \\
\hline Toplam & 70 & 70 & 140 \\
\hline
\end{tabular}

Kaynak: İSO (2017b) verilerinden derlenmiştir. 


\section{Aytuğ Sözüer, Esin Bengü Ceran ve Fatih Semerciöz}

2011-2013 döneminde, toplam aktiflerin ortalama yıllık değişimi yerli işletmelerde \%19,6; yabancl sermayeli işletmelerde \%12,9'dur (eşleştirilmiş iki grup $\mathrm{t}$ testi sonucu fark anlamlı, $p=0,036$ ). Aynı dönemde özkaynakların değişimi ise, yerlilerde $\% 20,4$; yabancı sermayelilerde $\% 21,3$ 'tür (aynı t testi sonucu fark anlamlı değil, $p=0,913$ ).

Yerli ve yabancı sermayeli işletmelerin performansı, öncelikle fark analizine tabi tutulmuştur. Eşleştirilmiş iki grup t testleri sonucunda, ROA $(p=0,384)$ ve $\operatorname{ROE}(p=0,096)$ açısından gruplar arası belirgin bir fark olmadığı tespit edilmiştir. Öte yandan bu bulgu, çalışmanın esas öngörüsü olan, iki grup işletmenin performanslarının benzer olduğu hipotezini desteklemek için (ikinci tür hatadan kaçınmak adına) yeterli görülmemiştir. Bu yüzden, iki farklı istatistikî karşılaştırma testine daha başvurulmuştur. Hesaplamada kullanılan veriler Tablo 2'de sunulmuştur.

Tablo 2: Grupların Ortalama, Standart Sapma ve Korelasyonları

\begin{tabular}{lcccc}
\hline & \multicolumn{2}{c}{ ROA } & \multicolumn{2}{c}{ ROE } \\
\hline & $\begin{array}{c}\text { Yerli } \\
\text { sermayeli } \\
\text { şirketler }\end{array}$ & $\begin{array}{c}\text { Yabancı } \\
\text { sermayeli } \\
\text { şirketler }\end{array}$ & $\begin{array}{c}\text { Yerli } \\
\text { sermayeli } \\
\text { şirketler }\end{array}$ & $\begin{array}{c}\text { Yabancı } \\
\text { sermayeli } \\
\text { şirketler }\end{array}$ \\
\hline Örneklem sayıSı & 70 & 70 & 70 & 70 \\
Ortalama & 8,08 & 7,12 & 14,48 & 9,47 \\
Standart sapma & 8,29 & 9,57 & 14,79 & 23,66 \\
Korelasyon & \multicolumn{2}{c}{$0,488 * * *$} & & $0,232 *$ \\
katsayısı & \multicolumn{3}{c}{} \\
\hline
\end{tabular}

${ }^{*} p<0,1 ; * * * p<0,01$

$\mathrm{Bu}$ benzerlik analizlerinden ilki eşdeğerlik testidir (İngilizcede equivalence test). Eşdeğerlik testi, iki gruba ait değerlerin belirli bir aralık içinde dağılımına ilişkin hipotez testleri için kullanılmaktadır (Rogers, Howard ve Vessey, 1993). Bunun bir yöntemi, iki tek kuyruklu t testidir. Bu teste göre, grupların hangi değerler arasında dağıım gösterdiği tespit edilmekte ve bu aralık bilinen bir tolerans dâhilinde ise grup skorları eşdeğer kabul edilmektedir. Öte yandan, ilgili yazında işletmelerin ROA ve ROE oranları açısından hangi aralıkta eşdeğer sayılacaklarına dair bir kıstasa rastlanmamıştır. Bu nedenle, sadece gruplara ait ROA ve ROE değerlerinin dağıım gösterdiği aralık tespit edilmiştir. Hesaplamalar sonucu yerli ve yabancı sermayeli işletmelerin ROA oranlarının $\pm \% 3,65$; ROE oranlarının $\pm \% 11,32$ aralıklarında dağıldığı anlaşılmıştır. Bu bulgudan, iradi olarak, ROA aralığının eşdeğer sayılabileceği fakat ROE aralığının eşdeğer kabul edilemeyeceği çıkarımı yapılmıştır. 
Yerli ve Yabancı Sermayeli İşletmelerin Kârlılıklarının Karşılaştırılması: Türkiye'deki Büyük Üretici Firmalar Örneği

Veriler arasındaki benzerliği ölçebilecek bir diğer yöntem, varyansların homojenliği varsayımını test etmektir. Eşleştirilmiş iki grup için varyansların homojenliği varsayımı Pitman-Morgan testiyle sınanabilmektedir (how2stats, 2017). Hesaplama sonucunda, ROA ölçütü için $(p=0,18)$ grupların benzeştiği varsayılabilirken; ROE ölçütü için $(p<0,001)$ bu saptama yapılamamaktadır. Bu bulgu bir önceki eşdeğerlik testinin de sağlaması niteliğindedir. Böylece, araştırma hipotezinin kısmen desteklendiği yargısına ulaşılmışır.

\section{DEĞERLENDİRME VE SONUÇ}

Dünyada ticaretin ve parasal hareketliliğin serbestleşmesi, modern ekonomik düzenin önemli araçlarındandır. Bunun bir yansıması olan doğrudan yabancı yatıımlar, uluslararası piyasalarda belirgin bir ağırlık yarattığı gibi, örgütsel alanların dinamiklerini ve işletmelerin davranışlarını da etkileyebilmektedir. Konu hakkında yapılan araştırmalar, akademik bilgi birikimine katkı sağlamanın yanında, yönetim alanındaki uygulamacılara ve politika yapıcılara da yön vermektedir. Genel itibariyle, dünyada ürün, hizmet, para ve işgücünün serbest dolaşımının olumlu olduğu kabul edilmektedir. Öte yandan, günümüz şartlarında, işletmelerin sermaye yapılarında yabancı yatıım bulunmasının işletmelere doğrudan etkisi üzerine akademik alanda fikir birliği bulunmamaktadır. Örneğin, belirli piyasalarda yerli ve yabancı sermayeli işletmeleri kurumsal performans açısından karşılaştıran çeşitli araştırmalar, önceki bölümde aktarıldığı üzere, farklı sonuçlara işaret etmektedir. Bu çalışma ile yazındaki mevcut tartışmaya, az irdelenmiş bir bağlamdan katkı sağlamak amaçlanmıştır.

Çalışmanın öngörüsü, yerli ve yabancı sermayeli büyük işletmelerin performanslarının eşdeğer olacağıdır. Buna gerekçe olarak, doğrudan yabancı yatırımların önemli bir kaynağı olan çokuluslu işletmelerden, faaliyet gösterdikleri ülkedeki yerli işletmelere doğru gerçekleşen taşma etkisi gösterilmiştir. Taşma etkisi, çokuluslu işletmelerin rekabette üstünlük sağlayacak özelliklerinin, belirli bir piyasada ve zaman içinde taklitçilik, işgücü hareketliliği ve rekabet yollarıyla diğer işletmelere sirayet etmesini yansıtmaktadır. Bu beklentiden hareketle, İstanbul Sanayi Odasının hazırladığı Türkiye'nin en büyük sanayi kuruluşları araştırmalarından bir veri seti derlenmiş; yerli ve yabancı sermayeli olarak ayrıştırılan toplam 140 işletmenin üç yıllık ortalama aktif kârlılık oranları ve özkaynak getirileri karşılaştırımıştır. Analiz sonucunda, işletme performanslarının aktif kârlıık ölçütüne göre eşdeğer sayılabileceği gösterilmiştir. Diğer taraftan, özkaynak getirileri iki grup arasında ne eşdeğer ne de anlamlı derecede 


\section{Aytuğ Sözüer, Esin Bengü Ceran ve Fatih Semerciöz}

farklı çıkmıştır. Bu durumu açıklamak için işletmelerin aktif ve özkaynaklarındaki değişimler göz önüne alınabilir. Hatırlanacak olursa, incelenen dönemde yerli işletmeler yabancı sermayeli işletmelere kıyasla aktiflerini daha yüksek oranda artırmıştır. Özkaynak değişimleri ise birbirine yakındır. Bu tespit, taşma etkisinin rekabet kanalıyla gerçekleştiğine; yerli işletmelerin piyasadaki konumlarını korumak amacıyla daha çok varlık yatırımı yapmış olabileceğine işaret etmektedir. Özkaynak artışlarındaki benzerlik ise, yerli işletmelerin varlık alımlarını kendi sermayeleriyle değil, borçlanma (kredi) yoluyla sağladıkları ipucunu vermektedir. Bu çıkarımın dayanaklarından biri 2008-2010 yılları ile 2011-2013 yılları arasında ortalama ticari kredi faizlerinin reel iki puan düşmüş olmasıdır (TCMB, 2017; TÜİK, 2017). Başka bir ifadeyle, yerli sermayeli işletmeler varlık alımlarını kredi yoluyla değil de daha çok öz sermaye artışıla gerçekleştirselerdi, özkaynak getirilerinin azalarak yabancı sermayeli işletmelerle eşdeğer olma intimali artacaktı. Keza, iki grubun özkaynak getirilerinin anlamlı derecede farklı çıkmaması da bu yorumu güçlendirmektedir. Özetle bu çalışmada, büyük işletmeler kapsamında, yabancı sermayeye özgü kabul edilen avantajların, yurt içi rekabette belirgin bir üstünlük yaratmadığına dair yaklaşım desteklenmiştir (Bellak, 2004). Bu durum, dünyada doğrudan yabancı yatırım hareketliliğinin artması ve ülkeler arası sınırların gevşemesine karşın, uluslararası stratejilerin akılcılığındaki sınırların daha da katılaştığına işaret etmektedir.

Bu çalışmadaki araştırma yöntemine dair en belirgin kısıtlar; verilerin orta vadeli bir dönemi kapsaması, gözlem sayısının sınırlı olması ve performans çıktısı hesaplanan şirketlerin faaliyet alanlarının heterojen dağılımı olarak sıralanabilir. Ayrıca, örneklemdeki işletmelerin tamamı halka açık olmadığından, sermaye yapısı ile piyasa değerlerindeki değişim kıyaslanamamıştır. Öte yandan, çalışmanın kapsamı dâhilinde, Türkiye'deki yerli ve yabancı sermayeli işletmelerin operasyonel etkinliklerinin ne oranda benzeştiğini tespit etmesi bakımından yazına katkı sağlayacağı düşünülmektedir. Bu sayede, araştırma verileri ileriki çalışmalara bir gösterge olabilecektir. Ayrıca, bundan sonraki benzer analizlerde, araştırma modellerinde doğrudan yabancı yatırımın hangi kaynaklardan geldiği ve sermaye iştirakinin düzeyi gibi unsurların da dikkate alınması tavsiye edilmektedir. 


\section{KAYNAKÇA}

Aitken, B.J. ve Harrison, A.E. (1999). Do domestic firms benefit from direct foreign investment? Evidence from Venezuela. The American Economic Review, 89(3), 605-618.

Al-Matari, E.M., Al-Swidi, A.K. ve Fadzil, F.H.B. (2014). The measurements of firm performance's dimensions. Asian Journal of Finance \& Accounting, 6(1), 24-49.

Aslanoğlu, E. (2000). Spillover effects of foreign direct investments on Turkish manufacturing industry. Journal of International Development, 12, 1111-1130.

Aydın, N., Sayım, M. ve Yalama, A. (2007). Foreign ownership and firm performance: Evidence from Turkey. International Research Journal of Finance and Economics, 11, 103-111.

Barbosa, N. ve Louri, H. (2005). Corporate performance: Does ownership matter? A comparison of foreign- and domestic-owned firms in Greece and Portugal. Review of Industrial Organization, 27(1), 73102.

Basti, E. ve Bayyurt, N. (2008). Efficiency performance of foreign-owned firms in Turkey. Transformations in Business \& Economics, 7/3(15), 20-30.

Bellak, C. (2004). How domestic and foreign firms differ and why does it matter? Journal of Economic Surveys, 18(4), 483-514.

Bilyk, O. (2009). Foreign ownership and firm performance: A closer look at offshore-owned companies in Ukraine. Yüksek Lisans Tezi, Kiev İktisat Fakültesi.

Birkinshaw, J.M. (1996). How multinational subsidiary mandates are gained and lost. Journal of International Business Studies, 27(3), 467-496.

Birkinshaw, J.M. (1997). Entrepreneurship in multinational corporations: The characteristics of subsidiary initiatives. Strategic Management Journal, 18(3), 207-229.

Brouthers, K.D. ve Hennart, J-F. (2007). Boundaries of the firm: Insights from international entry mode research. Journal of Management, 33(3), 395-425.

Bruno, R.L. ve Cipollina, M. (2014). FDI impact on firm performance in enlarged Europe: Evidence from a meta-regression Analysis. IZA Discussion Paper No. 8085, http://ftp.iza.org/dp8085.pdf (24.12.2015) 


\section{Aytuğ Sözüer, Esin Bengü Ceran ve Fatih Semerciöz}

Buckley, P. ve Casson, M. (1976). The future of the multinational enterprise. Basingstoke: Macmillan.

Canabal, A. ve White III, G.O. (2008). Entry mode research: Past and future. International Business Review, 17, 267-284.

Caves, R.E. (1996). Multinational enterprise and economic analysis. Cambridge: Cambridge University Press.

Chen, H. ve Hu, M.Y. (2002). An analysis of determinants of entry mode and its impact on performance. International Business Review, 11, 193-210.

DiMaggio, P.J. ve Powell, W.W. (1983). The iron cage revisited: Institutional isomorphism and collective rationality in organizational fields. American Sociological Review, 48(2), 147-160.

Dunning, J.H. (1977). Trade, location of economic activity and the MNEs: A search for an eclectic paradigm. P. Wijikman (Der.), The international allocation of economic activity (ss. 395-418). London: Macmillan.

Dunning, J.H. (1993). Multinational enterprises and the global economy. Harlow: Addison-Wesley.

Douma, S., George, R. ve Kabir, R. (2006). Foreign and domestic ownership, business groups, and firm performance: Evidence from a large emerging market. Strategic Management Journal, 27(7), 637-657.

Ertuna, B. ve Yamak, S. (2011). Foreign equity configurations in an emerging country: Implications for performance. European Management Journal, 29, 117-128.

Gedajlovic, E., Yoshikawa,T. ve Hashimoto M. (2005). Ownership structure, investment behaviour and firm performance in Japanese manufacturing industries. Organization Studies, 26(1), 7-35.

Gürbüz, A.O. ve Aybars, A. (2010). The impact of foreign ownership on firm performance, evidence from an emerging market: Turkey. American Journal of Economics and Business Administration, 2(4), 350-359.

Hymer, S.H. (1960). The international operations of national firms: A study of direct foreign investment. Doktora tezi, MIT Üniversitesi.

Hennart, J.F. (1982). A theory of multinational enterprise. Ann Arbor: University of Michigan Press.

Helpman, E., Melitz, M.J. ve Yeaple, S.R. (2004). Export versus FDI with heterogeneous firms. The American Economic Review, 94(1), 300316. 
Yerli ve Yabancı Sermayeli İşletmelerin Kârlılıklarının Karşılaştırılması: Türkiye'deki Büyük Üretici Firmalar Örneği

How2stats (2017). Pitman-Morgan test: Test the difference between correlated variances [Blog yazısı]. http://www.how2stats.net/ 2011/06/testing-difference-between-correlated.html (22.07.2017)

İSO (İstanbul Sanayi Odası) (2017a). Tarihçe ve metodoloji. http://www.iso500.org.tr/iso-500-hakkinda/tarihce-ve-metodoloji (20.07.2017)

İSO (İstanbul Sanayi Odası) (2017b). Geçmiş yıl verileri. http://www.iso500.org.tr/iso-500-hakkinda/gecmis-yil-verileri (20.07.2017)

Johanson, J. ve Mattsson, L.G. (1988). Internationalisation in industrial systems. M. Hood ve J.E. Vahlne (Der.), Strategies in global competition (ss. 287-314). New York: Croom Helm.

Johanson, J. ve Vahlne, J.E. (1977). The internationalization process of the firm: A model of knowledge development and increasing foreign market commitments. Journal of International Business Studies, 8(1), 23-32.

Koçtürk, M. ve Eker, M. (2012). Dünyada ve Türkiye'de doğrudan yabancı sermaye yatırımları ve çok uluslu şirketlerin gelişimi. Tarım Ekonomisi Dergisi, 18(1), 35-42.

Liu, Q, Lu, R. ve Qiu, L.D. (2017). Foreign acquisitions and target firms' performance in China. The World Economy, 40(1), 2-20.

Mihai, I.O. ve Mihai, C. (2013). The impact of foreign ownership on the performance of Romanian listed manufacturing companies. The International Journal of Management Science and Information Technology, 10(2), 106-122.

Markusen, J.R. (1995). The boundaries of multinational enterprises and the theory of international trade. The Journal of Economic Perspectives, 9(2), 169-189.

Morschett, D., Schramm-Klein, H. ve Swoboda, B. (2010). Decades of research on market entry modes: What do we really know about external antecedents of entry mode choice? Journal of International Management, 16, 60-77.

Notta, O. ve Vlachvei, A. (2008). Foreign-owned versus domesticallyowned firms: Evidence from Greece. New Medit, 4, 13-19.

Rogers, J.L., Howard, K.I. ve Vessey, J.T. (1993). Using significance tests to evaluate equivalence between two experimental groups. Psychology Bulletin, 113(3), 553-565. 


\section{Aytuğ Sözüer, Esin Bengü Ceran ve Fatih Semerciöz}

Rugman, A.M., Verbeke, A. ve Nguyen, Q.T.K. (2011). Fifty years of international business theory and beyond. Management International Review, 51, 755-786.

Togan, S. (2010). Turkey: Trade policy review, 2007. The World Economy, 33(11): 1339-1389.

TCMB (Türkiye Cumhuriyet Merkez Bankası) (2017). İstatistikler, parasal ve finansal istatistikler, bankalarca açılan kredilere uygulanan ağırlıklı ortalama faiz oranı. http://www.tcmb.gov.tr/wps/wcm/ connect/TCMB+TR/TCMB+TR/Main+Menu/Istatistikler/Parasal+ve +Finansal+Istatistikler/Faiz+Istatistikleri/Bankalarca+Acilan+Kredi (16.12.2017)

TÜİK (Türkiye İstatistik Kurumu) (2017). Temel istatistikler, enflasyon ve fiyat, yurt içi üretici fiyat endeksi. http://www.tuik.gov.tr/ UstMenu.do?metod=temelist (16.12.2017)

UNCTAD (United Nations Conference on Trade and Development) (2017). World investment report 2017, annex tables. http://unctad.org/en/ PublicationChapters/wir2017_AnnexTables_en.pdf (21.07.2017)

Vernon, R. (1966). International investment and international trade in the product life cycle. The Quarterly Journal of Economics, 80(2), 190207.

Werner, S. (2002). Recent developments in international management research: A review of 20 top management journals. Journal of Management, 28, 277-305.

Yaşar, M. ve Paul, C.J.M. (2007). Firm performance and foreign direct investment: Evidence from transition economies. Economics Bulletin, 15(21), 1-11.

Yeaple, S. (2003). The complex integration strategies of multinationals and cross country dependencies in the structure of foreign direct investment. Journal of International Economics, 60(2), 293-314. 